\title{
Work/Life Balance: A Cadre/Gender-Wise Assessment of Commercial Bank Employees
}

\author{
Danish Sultan 1 \\ Dr. M. Nadeem Hanif ${ }^{2}$
}

\begin{abstract}
In Pakistan, where the competition is intense in almost all industries, professionals spend more time at work than official duty hours in order to survive the rapidly changing environment. This has resulted in numerous compromises on other important fronts like cutting off from family and friends. It is assumed that work/life imbalance prevails more in developing nations with immense work pressures. To keep up pace with the growing demands of organizations and increasing responsibilities, one often neglects any or all strands of socializing. This gives rise to an imbalance which erupts as work/life conflicts for an individual and affects one's satisfaction in work and other activities. The purpose of this research is to determine the impact of work/life balance on employees of a commercial bank (in different branches) in Pakistan where men and women focus more on professional life and compromise on other dimensions of life which are: personal, family, and social. The survey included professionals working in public, private and foreign commercial bank branches. Five-point Likert scale was used to measure the three underlying constructs: 'work/life balance', 'organizational support' and 'support from others'. Data was analyzed using basic and descriptive statistics, factor analysis, correlation and t-test. The results indicate that majority of professionals are not satisfied with the balance between their work and life since greater number of hours are spent at work than the official duty timings. Moreover, females reported to have greater 'work/life balance', 'organizational support' and 'support from others' as compared to males. Males showed a higher tendency of developing stress-related diseases which were a consequence of increasing workplace demands and responsibilities.
\end{abstract}

Keywords: Work life balance, work life conflict, Pakistani commercial banks

\section{Introduction}

\subsection{Background of the Study}

There are several definitions of work life balance, but it is most accurately defined as a "systematic combination of work and life activities, so that working professionals can focus on other areas of their lives: personal life, family, work and the society where they carry out various roles as individuals in their lives" (Bailyn, Drago \& Kochan, 2001).

In the late 1970s, researchers started conducting studies on work/life balance to gain insights about creating a balance between work and personal life of individuals. In recent years, a significant increase has been observed in work due to constant up-gradation of information technology and an intense work environment that is getting competitive day-by-day.

${ }^{1}$ Danish Sultan is Assistant Manager, Human Resource Department, Scilife Pharma, Karachi, danish.sultan@gmail.com ${ }^{2}$ Dr. M. Nadeem Hanif is Senior Economist, State Bank of Pakistan, Karachi, muhammadnadeemhanif@yahoo.com \begin{tabular}{llll|l}
\hline JISR-MSSE & Volume 11 & Number 1 & Jaunary - June 2013 & 1
\end{tabular} 
Commitment to organizations and loyalty have been negatively affected by an environment where a lot is being demanded from employees in terms of performance. However, little or no job security is being provided in return. Numerous researchers thought that majority of domestic chores would be reduced and people would enjoy more leisure time yet work pressure has elevated to greater heights and reinforced low emphasis to recreational activities (Joshi et al., 2006).

Many employees, today, feel that their lives are increasingly burdened with family and other personal responsibilities while they are not able to give time to their personal interests. Similarly, it is often experienced by working men and women that they have to take time off from work or reduce their working hours to give time to their families. Therefore, it is very vital for organizations to understand the impact of work/life balance on working professionals for retaining employees (Williams, 2000). Work/life balance is quickly gaining popularity and currency around the globe. It is a much emphasized catchphrase which indicates that organizations are acknowledging the fact that their employees have to indulge in other chores besides work which equally require as much time and efforts as their work. It is about recognizing and acknowledging an individuals' need to seek out a balance between their work responsibilities and responsibilities outside their work domain. The employees enjoy flexible work environment provided to them and employers get in return higher commitment from their employees, increasing self-esteem within the organization and less turnover (Lockwood, 2003).

The need to research on work/life balance was realized by scholars and analysts during 1980s and 1990s when development of policies pertaining to benefits provided to the families of employees started surfacing. During that time, it was considered as an initiative taken to encourage women to work in organizations. The ambition behind such policies was to encourage and support working women who had children back at home. Gradually, work/life balance focused on all genders and distinguished other responsibilities apart from work. Now, it extensively covers guidelines, policies and strategies that recognize and respond to individual employee demands and needs. It allows individuals to spend more time apart from work and have time for other personal interests like spending more time with their families (Kanter, 1977).

As Lockwood (2003) views it, in most of the organizations today, the challenges of work/life balance are gaining immense popularity and attention. In order to cope up with the dynamic environmental changes that one is exposed to, human resources professionals are constantly seeking options to positively impact the performance of their employees, improving their motivation, morale and satisfaction. Keeping pace with workplace trends and retaining employees with valuable knowledge is a concern for all employers.

The work/life balance dilemma is a concern for all employers, the reason being that it has a direct impact on the employee satisfaction. A professional's life mostly revolves around four dimensions: personal life; professional life; social life and family life. A focus on any one of the dimensions and neglecting others might mean that the person will have to compromise on other dimensions. Therefore, maintaining an acceptable balance between work and life is important in determining employee satisfaction levels. 


\section{Research Methodology}

This research is descriptive in nature to ascertain and describe the characteristics of the three constructs: 'Work/life balance', 'Organizational support' and 'Support from others' in public, private and foreign sector commercial banks. Due to unavailability of data on Pakistan's employment industry pertaining to work/life balance, emphasis has been given to primary data collection. Quantitative analysis has been conducted on the data collected through a survey questionnaire. The questionnaire included nominal and ordinal measures to conduct exploratory and descriptive analysis. The questionnaire consisted of 28 questions, out of which 15 questions were designed to measure the three underlying constructs using 5-point Likert scale. Stratified random sampling technique has been used and the sample was divided into three subgroups: public sector banks; private sector banks; foreign banks. A random sample has been taken in each subgroup accordingly. Information was collected from a total of 348 respondents. The Gallup survey technique was used for calling up branches and conducting the survey over phone (Gallup Inc., 2010).

\section{Literature Review}

\subsection{Workplace Demands and Increasing Responsibilities}

Work/life balance may have different standpoints from the perspective of both the employees and employers. For an employee, work/life balance may be an obligation towards managing their commitment to work and giving time to their family and personal needs. Whereas for employers, they might view it as the need to create such a work environment and culture that enables the employees to fully concentrate on their work while they are performing their duties (Lockwood, 2003).

Factors that contribute towards creating an increasingly demanding workplace are many, for instance: global competition; increasing job responsibilities; workplace culture, so on and so forth. Traditional work patterns are constantly being challenged by technological advancements, business reengineering and restructuring and globalization. Individuals, families and households imposed to such changes are being affected intensely (Taylor, 2000). However, "the basic outline of the social contract, as it has emerged during the past several years, calls for workers to commit their best contributions and greatest energies to the job in return for interesting work, respectful treatment, developmental opportunities and an environment that responds to individual needs. Where those provisions conflict (e.g., the degree of commitment and energy expected by employers versus the flexibility required by employees), the expertise of both diversity management and work/life professionals will be critical to find win-win solutions" (Fineman, 1999).

The organization's culture also plays a pivotal role in determining the importance of work/life initiatives within a workplace (Gambles, 2006). For organizations, it is extremely essential to integrate a "corporate culture that encourages employees to look at business in an entirely different way and supports and accepts employees as individuals with priorities beyond the workplace" (Lockwood, 2003). How important is an organization's culture can also be highlighted from explanation given by Sandra Burud who works at Bright Horizons Family Solutions (Lockwood, 2003). She discussed the work-life initiatives and how they should be incorporated in business strategies. According to her, "employers are realizing that work

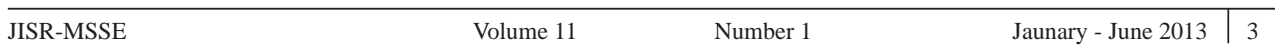


should be intrinsically interesting and satisfying to employees and these are the folks who produce the best work. The manager's job is to get out of the way. The move from extrinsic rewards to intrinsic rewards has an impact on work/life initiatives" (Parus, 2000).

One way to assess an organization's readiness to opt for work/life balance is by identifying how employees perceive the willingness of their employer to support them in matters within and outside their work domain. Beauvais, Lyness and Thompson conducted a research in 1999 where they studied and established relationships between the organizational environment and culture to which employees were exposed to and worked in; the degree to which employees availed benefits pertaining to work/life balance, the magnitude of conflict arising from time spent at work and time given to families; and the willingness of employees to work with their incumbent employers for a pre-determined time period. The research findings stated that as organizations tend to provide more work and family related benefits to their employees, employees show greater loyalty and commitment, indulge less frequently in work and nonwork conflict and it becomes easier for organizations to retain employees. It is interesting to note that the results of the research affirmed that as organizational culture becomes more supportive towards the needs of employees, attitudes and behaviors of employees may consequently support organizations. In such cases, employees show greater commitment with lesser enthusiasm towards resigning (Thompson, Beauvais \& Lyness, 1999).

\subsection{Personal/Family/Social Life Values}

Over the years, personal life and family values have gained significant importance which most professionals do not easily compromise on, or disregard, despite increasing workplace demands. Over time, almost all professionals have started to focus on managing their time to cope up with non-work activities rather than spending most of their time at work. At the same time, increasing occurrences of natural disasters and terrorism have made people to rethink about their priorities in life and what else they want to achieve apart from their professional objectives (Lockwood, 2003).

In a study, Parasuraman and Greenhaus (2002) stated that there is always a fraction of workforce which is continuously facing pressures from their work and families simultaneously and even so, they have support from nowhere. It is essential to understand that conflict between work and life arises when people are not able to fulfill the objectives of their different roles in life due to time and energy constraints. Fulfilling the needs and objectives of one role becomes gradually more challenging by participating in another role (Duxbury \& Higgins, 2001).

This can further be clarified by the highly acclaimed work of Friedman and Greenhaus (2000), which brought forth new evidence to provide a better understanding of how individuals and employers make choices and decisions regarding priorities given to work and family. Friedman and Greenhaus surveyed more than eight hundred individuals and professionals who placed emphasis on family, work and ethics. They found through the study that "Work and family, the dominant life roles for most employed women and men in contemporary society, can either help or hurt each other." (Friedman \& Greenhaus, 2000)

Conflict between work life, personal life and family values is also evident from the fact that many working professionals encounter an imbalance between different life roles they play, 
for instance the role of child, parent, colleague, spouse, friend, employee etc. Over the years, working professionals have been increasingly exposed to greater stress, while putting at stake their mental and physical wellbeing. This has ultimately reduced their satisfaction levels in all aspects of life. This has also resulted in a change of attitude from working professionals towards their organizations and job responsibilities. As a matter of fact, employees are becoming more stressed because of their work and they seem to be less satisfied with their life. In turn, their loyalty and commitment towards their employers is constantly declining, due to which turnover and absenteeism in organizations is becoming very common. Because of the increasing workplace demands, employees have to spend more time at work and in many instances, they have to take their work back home, thus extending their work hours (Duxbury \& Higgins, 2001).

\subsection{Work/Life Dimensions}

\subsubsection{Personal Life}

The personal life is a concern with person's own needs and responsibilities to himself. The recreational activities and leisure time required to keep people energetic and emotional for their mental well-being is unfortunately fading away these days (Greenhaus \& Beutell, 1985). According to some researches people who are disposed to high level of work-load in their organizations are also prone to health-related problems due to physical and mental stress they go through. Thus in such organizations the cost of health insurance claims is high which ultimately affects the professional life of a person as they are unable to fulfill their personal demands such as complete rest and other recreational needs (Chandola et al., 2004).

\subsubsection{Family Life}

Family life is more concerned with roles and responsibilities you have regarding your spouse, parents and children. They all have certain demands, for example, children need care and time of parents, spouse and parents need time and support. If these demands are not fulfilled it may give rise to work/life imbalance and ultimately hit the performance of the person (Kahn \& Long, 1988).

A research indicated that working professionals who spend more time at work and are overloaded with their job responsibilities usually compromise on giving time to their families, for which they have to face negative attitudes from their family members at home. This is turn generates a negative attitude from employees towards their work and home, whereas their family satisfaction also reduces and they are not able to participate much in family activities because of increasing workplace demands (Lyons, Duxbury \& Higgins, 2006).

\subsubsection{Work Life}

Organizations are becoming greedier and greedier in terms of demanding more time and commitment from employees because of globalization and challenging work environment (Brandth \& Kvande, 2001). Jacqueline Watts also identified in her study that project-based work is a growing concept nowadays which leaves employees with insufficient time to spend on activities outside their work domain (Gregory \& Milner, 2009).

\begin{tabular}{lll|l}
\hline JISR-MSSE & Volume 11 & Number 1 & Jaunary - June 2013
\end{tabular}


According to another research, professionals who were overloaded with work witnessed a greater conflict between managing their time spent at work and with their families. Such professionals showed greater job dissatisfaction and experienced a lot of stress at work and home. Organizations in which these professionals were employed faced greater challenges of absenteeism and turnover. Irrespective of being provided with various employee assistance programs, professionals working in these organizations showed a higher tendency of quitting their jobs and in majority of the cases, they were not even willing to rate their employers as "above average" in terms of being a suitable organization to work with (Lyons, Duxbury \& Higgins, 2006).

\subsubsection{Social Life}

Social scientists dealing with human resources (HR) issues and linking it to the development of organizational behavior (OB) have come a long way and they now understand as to how the work life of an employee effects his social life and how these are intertwined and vice versa. The Human Resource and Organizational Behavior researchers have paid great attention to conflicts arising between work and family life, as well as conflicts arising from focusing too much on work which results in a rapidly declining social life, which will ultimately have an adverse effect on the organization's profitability and employees' productivity (Greenhaus \& Beutell, 1985).

Workers who are young and are bachelors may not face marital problems arising from the married life; however, work life conflict may arise because of the incomplete tasks which need to be performed by them. Their day-to-day responsibility may include having to interact with people in different social groups. Thus, working professionals who live independently and do not have any nuclear family may also experience work-life conflict one way or the other. Irrespective of their family structure, many working professionals have the need to associate themselves socially with different groups and it is assumed that tradeoffs are made between work and leisure time. Living in a metropolis these days, it is imperative that worklife with social interaction is essentially very important. The necessity to investigate factors that reflect the social needs of the current workforce trends is therefore being highly emphasized upon (Premeaux, Adkins \& Mossholder, 2007).

\subsection{Work/Life Balance and the Banking Sector}

The banking sector in Pakistan is one of the major sources of financial resource deployment in the country. Since the time of independence, Pakistan has faced unavailability of sufficient financial mechanisms, thus resulting in an increase in the underdevelopment of capital and money markets. Therefore, the role of banking sector in Pakistan to provide financial stability in the country has been highly emphasized upon time and time again. It has been observed not just in Pakistan, but in many different economies across the world, that different financial policies and frameworks have been instigated to strengthen the development and restructuring of the banking sector (Khalid \& Hanif, 2005).

However, with the advent of time, globalization and technological advancements have given rise to an increasingly competent and challenging work environment. Rapid growth and expansion of the banking operations in the country have put tremendous burden and pressure on the employees working in the banking sector. In recent times, recession and downsizing 
has further increased the stress levels of employees to new heights. This has mostly resulted in employees compromising on their personal, family and social time while focusing more on the increasing demands of their workplace.

\section{Data Analysis and Findings}

\subsection{Construct Validity}

The questionnaire was designed by using five-point Likert scale to measure three main constructs: 'Work/life balance'; 'Organizational support'; and 'Support from others'. Seven questions were developed to measure the construct 'Work/life balance', four questions to measure 'Organization support' and another four questions to measure 'Support from others'.

In order to check multidimensionality in scales and whether the variables were measuring the underlying constructs, exploratory factor analysis was conducted with principal components analysis methodology. The reason for doing so was to understand the structure of variables and the extent to which they were measuring the underlying constructs.

Principal components analysis (PCA) was performed on the 15 questions of the five-point Likert scale. The appropriateness and relevance of data for factor analysis was evaluated before performing PCA (see Table 1 in appendix). The Kaiser-Meyer-Oklin (KMO) test's value was 0.885 which exceeds the suggested value of 0.6 (Kaiser, 1970, 1974), indicating appropriate and reliable use of factor analysis. Statistical significance was reached through Bartlett's Test of Sphericity ( $\mathrm{p}<0.05$; Bartlett, 1954), which supported the factorability of the correlation matrix. Principal component analysis affirmed the presence of three components with eigen values exceeding 1, explaining a total of $70.1 \%$ of the variance (see Table 2 in appendix). Therefore, the three components were retained for further analysis.

To aid in the interpretation of these three components, oblique rotational technique was used with Oblimin rotation methodology on the assumption that all components were intercorrelated. The Pattern Matrix shows the factor loadings after rotation (see Table 3 in appendix). The questions loading on component 1 represents the construct 'Work/life balance', component 2 represents 'Support from others' and component 3 represents 'Organizational support'. Negative loadings on 'Organizational support' suggest that that the questions loading on the component are related with it in the opposite direction. There is no indication about the strength of relationship between the questions and the components based on the sign of factor loadings.

It is essential to note here that as per the initial assumption, all of the questions successfully loaded on the constructs/components they were designed to measure, except for only question 19 which loaded on the first component representing the construct 'Work/life balance'. However, when the questionnaire was designed, question 19 was assimilated with the construct 'Organizational support'. Question 19 has been retained to measure the construct 'Organizational support' rather than 'Work/life balance' as it had the lowest extracted communality or shared variance with the components and on the conceptual assumption that it was initially designed to measure the organization's flexibility towards encouraging or discouraging their employees to work during Rest and Recreational leave.

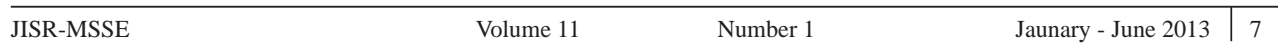




\subsection{Scale Reliability}

Reliability analysis was conducted separately for the three underlying constructs/subscales to check the reliability of each subscale: 'Work/life balance'; 'Organizational support'; and 'Support from others'.

'Work/life balance' had the highest Cronbach's alpha coefficient of 0.94. 'Organizational support' reported Chronbach's alpha coefficient of 0.77. 'Support from others' had the lowest Chronbach's alpha coefficient of 0.75 . Since Cronbach's alpha values for all three subscales are greater than 0.7 , the internal consistency reliability of the scales is considered to be acceptable.

\subsection{Profile Analysis}

\subsubsection{Gender}

Majority of the respondents employed in the commercial banks who responded to the questionnaires were males, with a presence of $60 \%$, whereas $40 \%$ of the respondents were females. The respondents were selected at random from the commercial bank branches based on Gallup survey technique; therefore, the results are not to be interpreted as being gender biased.

\subsubsection{Banking Sector Type}

Majority of the respondents belonged to private sector commercial bank branches (43\%), followed by respondents employed in the public sector commercial bank branches $(30 \%)$ and foreign commercial bank branches (27\%), respectively. It is also essential to note that private sector had the most number of branches. The number of branches operating in the public sector was slightly less than the private sector. Foreign commercial bank branches had the lowest presence compared to private and public sector.

\subsubsection{Age Group of Respondents}

Most of the respondents belonged to the age group of 20-30 years (46\%). As the age brackets increased, the percentage of respondents falling under the corresponding age groups gradually decreased, with lesser numbers between $30-40$ years $(35 \%)$ and even fewer in $40-50$ years age group (14\%). Age group of 50-60 years had the least number of respondents (6\%).

It can be reflected from this information that majority of the respondents employed in commercial bank branches were young individuals, both males and females. This also portrays the preference of banks placing dynamic and energetic individuals in the branches since most of the customer interaction occurs in the bank branches. The younger an individual is, the greater capacity they have to enthusiastically deal with customer interactions in the banking sector on daily basis.

\begin{tabular}{l|llll}
\hline 8 & Jaunary - June 2013 & Volume 11 & Number 1 & JISR-MSSE
\end{tabular}




\subsubsection{Marital Status}

Majority of the respondents were not tied in the matrimonial bond yet $(61 \%)$. However, a greater number of females were married compared to males (43\% vs. $35 \%$ ). Lesser number of unmarried respondents attributed to a greater number of respondents in the age group of 20-30 years since in this age group, people are usually more focused towards establishing a career and settling down in their professions before getting married.

\subsubsection{Living Status}

Most of the respondents, either married or unmarried, lived with their families and/or parents/siblings $(64 \%)$, followed by respondents who were married and lived with their spouse/children (28\%). Very few respondents lived alone (8\%). This information also reflects that family support will play a determinant role in individuals' lives and will be strongly associated with their work/life balance.

\subsubsection{Importance of Work/life Balance}

Nearly all of the respondents who were either living with their families or alone value the importance of Work/life balance (95\%). Very few respondents regarded it as being not important $(5 \%)$.

\subsubsection{Hours Spent at Work}

Majority of the respondents spent 9-10 hours at work (39\%). In most of the banks, official work hours range between 8 to 9 hours and only $21 \%$ of the respondents were observed spending this much time at work. A significant number of respondents also spent 10-12 hours at work $(29 \%)$, which is beyond the official working hours of almost all banks. Fewer respondents spent more than half of their day working $(7 \%)$ and the least number of respondents spent 7-8 hours at work (4\%).

It is considerable to note here that majority of males spent more hours at work as compared to females (9-10 hours: $41 \%$ vs. $36 \%$; $10-12$ hours: $38 \%$ vs. $16 \%$; more than 12 hours: $11 \%$ vs. $1 \%)$. Most of the females as opposed to males spent time according to the official banking hours (43\%), and their numbers declined as the working hours increased. However, very few males were observed spending time at work according to the official banking hours $(6 \%)$.

\subsubsection{Occurrence of Dining Out with Family}

Majority of the respondents spent time with their families to dine out at least once in a month $(51 \%)$. Fewer respondents dined out only on occasions and festivals $(24 \%)$ followed by those who dined out with their families at least once in a week $(21 \%)$. There were exceptionally few respondents who never dined out with their families (4\%). However, the frequency of dining out with families once in a month was greater for males $(57 \%$ vs. $42 \%)$. As for females, they dined out more frequently than males on weekly basis (44\% vs. $5 \%$ ). The trend changes for males who dined out more frequently than females on occasions and festivals (32\% vs. $13 \%)$. 


\subsubsection{Occurrence of Dining Out with Friends}

When it comes to dining out with friends, majority of the respondents dined out at least once in a month (59\%), followed by those who dined out with friends either once in a week $(20 \%)$ or on different occasions and festivals $(20 \%)$. Very few respondents dined out on daily basis $(1 \%)$, or never spent time to dine out with friends $(1 \%)$. Males dined out with friends more often than females at least once in a month $(63 \%$ vs. $51 \%)$ or on different occasions and festivals (26\% vs. 9\%). However, for females, the frequency of dining out on weekly basis was far greater than that of males $(37 \%$ vs. $8 \%)$.

It is evident that most of the respondents preferred spending time with friends to dine out rather than with their families, even if the numbers were restricted to dining out at least once in a month or on different occasions and festivals.

\subsubsection{Recreational Leave}

Almost all of the respondents stated that their organizations provide them with mandatory rest and recreational leave $(99 \%)$, with extremely few respondents disagreeing with the statement (1\%). It is essential to note here that State Bank of Pakistan, the regulatory central banking authority in Pakistan, has imposed policies which ensure that employees working in financial institutions should be given compulsory rest and recreational leave on annual basis.

\subsubsection{Stress-Related Diseases}

Majority of the respondents were suffering from stress related diseases (53\%), and more astonishingly, males were exposed to such diseases far much greater than females $(70 \% \mathrm{vs}$. $28 \%$ ). The information is quiet alarming since stress related diseases can be very unhealthy for individuals, especially those who are working professionals. More importantly, this information reflects health conditions of males in the banking sector who are tumbling towards living their lives under more stressful conditions with their stress levels on the rise. This indeed have a negative impact on their work and life activities.

Out of those respondents who were suffering from stress-related diseases, majority were exposed to frequent headaches (74\%), followed by respondents who underwent hypertension $(35 \%)$. Fewer respondents reported suffering from obesity (15\%) and other kinds of stress related diseases $(14 \%)$. None of the respondents were diabetic. This is attributed to the fact that most of the respondents belonged to an age group of 20-30 years and it is uncommon that people develop diabetes during early years of their lives.

Although nearly two-third of males and one-third of females reported suffering from stressrelated diseases, majority of them suffer from frequent headaches which were immensely common among both genders. There are many different reasons associated with having frequent headaches, however, it can have a substantial impact on an individual's health and as well as their work and life activities.

\begin{tabular}{l|llll}
\hline 10 & Jaunary - June 2013 & Volume 11 & Number 1
\end{tabular}




\subsubsection{Working Out/Physical Exercises}

Majority of respondents do not exercise at all (79\%), which was the case with both males and females. Although greater number of males as compared to females involved themselves in some kind of fitness activities, however, the numbers for both males and females who reported being involved in such activities were quite low ( $24 \%$ vs. $15 \%)$.

\subsubsection{Duration of Workout/Physical Exercises}

Out of those respondents who were involved in some kind of work out or physical exercises, majority of them devoted around half an hour in doing so (49\%) with fewer respondents spending half an hour to one hour for such activities (47\%). The least number of respondents got enough time to spend less than half an hour in fitness activities (4\%). It is essential to note that none of the respondents spent more than an hour for workouts or physical exercises for both genders.

On a comparative note, greater number of males spent half an hour in fitness activities than females (51\% vs. $43 \%)$. Females were more devoted in spending half an hour to an hour in such activities as compared to males (57\% vs. $43 \%$ ).

\subsubsection{Satisfaction with Balance between Work and Life}

Majority of the respondents disagreed with being satisfied with the current balance between their work and life (40\%), followed by respondents who were not at all happy with their work/life balance (23\%). Fewer respondents reported satisfaction with the balance between their work and life (16\%), whereas the least number of respondents were very happy in this regard $(7 \%)$.

Males reported greater dissatisfaction with their work/life balance as compared to females (disagree: $51 \%$ vs. $23 \%$; strongly disagree: $34 \%$ vs. $7 \%$ ). Females showed greater satisfaction towards the balance between their work and life (agree: $35 \%$ vs. $4 \%$; strongly agree: $12 \%$ vs. $4 \%)$.

\subsubsection{Imbalance between Work and Life on Job Satisfaction}

Majority of the respondents strongly felt that an imbalance between work and life plays an important role in deciding the satisfaction with their jobs (49\%), whereas fewer respondents agreed with the importance of work/life imbalance affecting their job satisfaction (45\%). Respondents who were unsure whether such an imbalance had anything to do with their job satisfaction were very few $(6 \%)$. It is essential to note that none of the respondents thought or felt that an imbalance between work and life had no impact on job satisfaction.

\subsection{Descriptive Analysis}

Each construct was measured using five-point Likert scale, where ' 1 ' reflected the least level of favorability and ' 5 ' the highest level of favorability. Descriptive analysis revealed that the overall favorability for the three underlying constructs: 'Work/life balance', 'Organizational

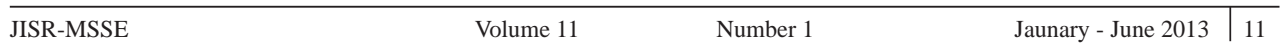


support' and 'Support from others' falls at the lower side of the scale with mean less than 3 (see Table 4 in appendix). On a comparative note, however, 'Organizational support' indicates the least level of favorability whereas 'Work/life balance' indicates greater favorability than the other two constructs. Standard deviation for all three constructs is less than one which indicates that there is low variance among the responses from the mean scores of the constructs.

\subsection{Correlation between Constructs: Work/Life Balance, Organizational Support and Support from Others}

Pearson product-moment correlation was used to investigate the relationship between 'Work/life balance', 'Organizational support' and 'Support from others' (see Table 5 in appendix). The appropriateness and relevance of data was evaluated for normality, linearity and homoscedasticity before performing the correlation analysis.

There was a strong, positive correlation between Work/life balance' and 'Organizational support' ( $\mathrm{r}=0.64, \mathrm{p}<0.0005)$. 'Organization support' explains nearly $40 \%$ of the variance in 'Work/life balance'. In other words, as 'Organizational support' increases, so does 'Work/life balance'.

Similarly, there was also a strong, positive correlation between 'Work/life balance' and 'Support from others' ( $\mathrm{r}=0.50, \mathrm{p}<0.0005)$. 'Support from others' explains nearly $25 \%$ of the variance in 'Work/life balance'. In other words, as 'Support from others' increase, 'Work/life balance' also increases. Comparatively, 'Organizational support' has a greater magnitude of shared variance on 'Work/life balance' than 'Support from others', although both are highly correlated with 'Work/life balance'.

It is also essential to note that 'Organization support' and 'Support from others' are also positively correlated with each other, although the strength of relationship has a medium effect. This indicates that with an increase in 'Organizational support', 'Support from others' also increase, but to a mediocre extent.

\subsection{Testing Differences between Males and Females for Correlation Coefficients of Work/Life Balance, Organizational Support and Support from Others}

Correlation coefficients of 'Work/life balance', 'Organizational support' and 'Support from others' were compared for males and females to test the strength of relationship between the variables for the two separate groups (see Table 6 in appendix).

For males, correlation between 'Work/life balance' and 'Organizational support' was $r=0.49$, while for females, it was slightly higher, $r=0.66$. Similarly, for males, correlation between 'Work/life balance' and 'Support from others' was $r=0.40$, while for females, it was again higher, $\mathrm{r}=0.67$.

\begin{tabular}{l|llll}
\hline 12 & Jaunary - June 2013 & Volume 11 & Number 1
\end{tabular}


Each of the $\mathrm{r}$ values were converted into standard scores also referred to as to $\mathrm{z}$ scores. This was done to ensure having normal sampling distributions. The $\mathrm{z}$ values which correspond with each of the $r$ values are:

\section{Males}

$\mathrm{r}=0.49 ; \mathrm{n}=210 ; \mathrm{z}=0.530$ (Organizational support)

$\mathrm{r}=0.40 ; \mathrm{n}=210 ; \mathrm{z}=0.430$ (Support from others)

\section{Females}

$\mathrm{r}=0.66 ; \mathrm{n}=138 ; \mathrm{z}=0.802$ (Organizational support)

$\mathrm{r}=0.67 ; \mathrm{n}=210 ; \mathrm{z}=0.811$ (Support from others)

The $\mathrm{z}$ (observed value) were calculated for both 'Organizational support' and 'Support from others' correlations with 'Work/life balance'.

The z(observed value) for correlation between 'Work/life balance' and 'Organizational support' was -2.46; for correlation between 'Work/life balance' and 'Support from others', it was -3.44 . Both of these values are outside the specified limits $(-1.96<\mathrm{z}$ (observed value $)<$ 1.96), therefore conclusion can be drawn that there is a significant difference in the strength of correlations of 'Work/life balance' with 'Organizational support' and 'Support from others' respectively. Both 'Organizational support' and 'Support from others' explain significantly more variance in 'Work/life balance' for females than for males.

\subsection{Comparing Mean Scores of Males and Females for Work/Life Balance, Organizational Support and Support from Others}

To compare the mean scores of males and females for the three underlying constructs: 'Work/life balance'; 'Organizational support'; and 'Support from others', independentsamples t-test was conducted (see Table 7 in appendix). The appropriateness and relevance of data was evaluated for normality, level of measurement, random sampling and independence of observations before performing the t-test.

Equal variances have been assumed for all three constructs as the significance values for 'Work/life balance', 'Organizational support' and 'Support from others' for Levene's test for equality of variances are all greater than 0.05 .

To check if differences between males and females are present in all three constructs, Sig. (2-tailed) values were examined. All values are less than 0.05 , which indicates that there is a significant difference in the mean scores of males and females for 'Work/life balance', 'Organizational support' and 'Support from others'.

The magnitude of the differences between males and females for the three underlying constructs were calculated using effect size statistics (eta squared).Effect size for the three constructs was as follows:

Work/life balance $=0.33$; Organizational support $=0.13$; Support from others $=0.03$

There were significant differences in scores for males and females on all three constructs 
respectively. The magnitude of differences in the means were very large for 'Work/life balance' (eta squared $=0.33$; mean for males $=2.47$; mean for females $=3.43$ ). For 'Organizational support', the magnitude of differences were sufficiently moderate (eta squared $=0.13$; mean for males=2.27; mean for females=2.70). However, for 'Support from others', the differences between the mean scores had a small effect (eta squared $=0.03$; mean for males $=2.59$; mean for females=2.82).

\section{Discussion}

This study was instigated with the notion that a professional's life revolves mostly around four essential dimensions of life: professional; family; personal; and social. When too much focus is given to any specific dimension while other dimensions are neglected, an imbalance is created. In Pakistan, the banking sector is very competitive. It is commonly observed and this study confirms that people tend to spend more hours at work which leads to an imbalance between their work and life. Through this research, an understanding was developed as to why work/life balance is important and what factors are attributed in maintaining a meaningful balance between work and life of individuals.

The primary focus was mainly on two factors that influence a balance or imbalance between different dimensions of life: workplace demands and increasing responsibilities; and personal/family/social life values. These factors provided the conceptual grounds for this study to relate 'Work/life balance' with 'Organizational support' and 'Support from others'. It is also evident that a resulting conflict between work and life plays an important role in affecting the satisfaction level of employees.

There are many factors that create an increasingly demanding workplace, a few of them being global competition, increasing job responsibilities and workplace culture. Yet the consequence of it is more or less the same where professionals end up spending more time at work than their official work timings. This can dramatically create an imbalance between work and life since less time is given to other dimensions of life such as personal, family and social.

Today, many professionals are experiencing difficulties in balancing their role towards their social, family and personal lives. Employees are developing a worrying attitude towards their employers and jobs are becoming more stressful. They are either devoting a greater portion of the day to work at the office, often exceeding their work timings, or take work home for completion. This study reflected that majority of the professionals employed in commercial bank branches were not satisfied with the current balance between their work and life. This was particularly a major concern for males as compared to females. Such psychological impact is caused by various factors including highly competitive banking sector dynamics, the work pressures which the professionals are exposed to and the support from their family and friends to maintain a balance between work and life. Inability to achieve such a balance can upset their association with their personal, family and social life dimensions, which results in individual's dissatisfaction towards work.

It is noteworthy to observe that most of the respondents acknowledged the importance of work/life balance and its impact on job satisfaction. It is also evident from this study that majority of the people working in commercial bank branches spent more time at work than their official work timings, a concern more immensely endured by males than females. This

\begin{tabular}{l|llll}
\hline 14 & Jaunary - June 2013 & Volume 11 & Number 1 & JISR-MSSE
\end{tabular}


leads to an imbalance between work and life where work takes major portions of time that would be preferred in meeting personal, family and social life demands. This again highlights that personal, family and social life demands are not being met. Employees are expressively feeling that the amount of time available to them for their life outside work is continuously reducing. Employers should realize that it is essentially very important that employees regard their work as interesting and satisfying and only then will the employees be able to give their best to work.

This study reflected that most of the males as compared to females were suffering from stressrelated diseases, with frequent headaches being the most common syndrome. This is quite distressing, since it can have adverse effects on an individual's health, which in turn can have a negative impact on their work and life activities. With increasing work pressures and long working hours, individuals are continuously putting their health at stake. It can also be supported from this study that most of the commercial bank employees do not undergo any physical exercises on regular basis. Health benefits of physical exercises are proven to combat stress effectively.

It was revealed in this study that organizational support and support from family and friends play an important role in helping individuals to achieve a greater work/life balance. The greater the support from organization, family and friends, the better the work/life balance will be. Compared to support from others, organizational support is more crucial towards helping individuals in seeking satisfaction between their work and life. Interestingly, monetary and non-monetary benefits are closely related to work attitudes. Therefore, the extent to which organizations provide monetary and non-monetary benefits to employees influence professionals to compromise over work/life balance to some extent if they are being compensated above their desired expectations.

Since a positive relationship has also been established between organizational support and support from others, it can be safely assumed that as organizations become more flexible in helping employees achieve work/life balance, support from others also increase since the individuals are able to spend more time with family and friends. However, if organizations take up most of the their employees' time, they will not be able to meet their commitments with friends and family, which will eventually result in increasing demands from the latter in terms of time spent with them. This will again upset the individual's balance between work and life.

It is also evident from this study that females have a greater variability than males in maintaining a proper work/life balance through organizational support and support from others. It is more likely that work/life balance, organizational support and support from family and friends are greater for them as compared to males.

If employers provide monetary and non-monetary benefits such as good remuneration packages, excellent perks, job security and various other benefits to employees, they willingly compromise over work/life balance for the time being. Yet the psychological impact of work on employees cannot be ignored in the long run. An imbalance between work and life will tend to decrease their satisfaction levels over time. 


\section{Conclusion}

It is evident from the study findings, when more time is allocated to work and less to different dimensions of life, mainly personal, family and social, it results in employee dissatisfaction in the long run. It was found in this study that when professionals are not able to fulfill the desired needs of their personal, family and social life because of increasing work pressures and demands, they tend to be less motivated over time. This immensely contributes in employee dissatisfaction toward attaining a balance between work and life, which was the case with majority of the professionals. This study also reveals that despite acknowledging the importance of work/life balance, majority of the professionals spend more time at work than their official work timings. This was a contributing factor towards sufferance from stressrelated diseases, with frequent headaches being the most common health issue. More astonishingly, males were exposed to stress-related diseases far greater than females. Also, 'organizational support' and 'support from others' explained more variance in 'Work/life balance' for females as compared to males. Females reported to have a greater work/life balance, support from organization, family and friends.

Work/life balance-related policies and practices should be given due consideration and attention in organizations which will in turn make employers more flexible, perceptive and responsive towards the needs of employees. This will eventually make it easier for employees to have time for other chores in life apart from work. This would also translate to a greater employee commitment and satisfaction and less work/life conflict.

\section{References}

Bailyn, L., Drago, R., \& Kochan, T. (2001). Integrating work and family life: a holistic approach. Cambridge, MA: Massachusetts Institute of Technology.

Bartlett, M. S. (1954). A note on the multiplying factors for various chi square approximations. Journal of the Royal Statistical Society, 16(B), 296-298.

Brandth, B., \& Kvande, E. (2001). Flexible work and flexible fathers. Work, Employment and Society, 15(2), 251-267.

Cohen, J.W. (1988). Statistical power analysis for the behavioral sciences (2nd ed.). Hillsdale, NJ: Lawrence Erlbaum Associates.

Chandola, T., Martikainen, P., Bartley, M., Lahelma, E., Marmot, M., Michikazu, S., \& Kagamimori, S. (2004). Does conflict between home and work explain the effect of multiple roles on mental health? A comparative study of Finland, Japan, and the UK. International Journal of Epidemiology, 33(4), 884-893.

Duxbury, L.E., \& Higgins, C.A. (2001). Work-life balance in the new millennium: where are we?: where do we need to go? (Vol. 4). Ottawa: Canadian Policy Research Network.

Fineman, M. (1999). Why diversity professionals should care about work/life balance? Mosaics, 5(6), 6-7.

\begin{tabular}{l|llll}
\hline 16 & Jaunary - June 2013 & Volume 11 & Number 1
\end{tabular}


Friedman, S.D., \& Greenhaus, J.H. (2000). Work and family-Allies or enemies? What happens when business professionals confront life choices. New York: Oxford University Press.

Greenhaus, J.H., \& Beutell, N. J. (1985). Sources of conflict between work and family roles. Academy of Management Review, 10(1), 76-88.

Gregory, A., \& Milner, S. (2008). Editorial: work-life balance: a matter of choice?. Gender, Work and Organization, 16(1), 1-13.

Gallup (Inc.). How are polls conducted?. (2010). Retrieved July 26, 2013, from http://www.gallup.com/poll/File/125927/How\%20Are\%20Polls\%20Conducted\%20 FINAL.pdf

Joshi, S., Leichne, J., Melanson, K., Pruna, C., Sager, N., Jo, C., \& Williams, K. (2006). A case of social responsibility or competitive advantage? Journal of Work/life Balance. Atlanta, GA: Georgia Institute of Technology.

Kahn, S.E., \& Long, B.C. (1988). Work-related stress, self-efficacy, and well-being of female clerical workers. Counseling Psychology Quarterly, 1(2-3), 145-153.

Kaiser, H. F. (1970). A second generation Little Jiffy. Psychometrika, 35, 401-415.

Kaiser, H. F. (1974). An index of factorial simplicity. Psychometrika, 39, 31-36.

Kanter, R. (1977). Work and family in the United States: a critical review and agenda for research and policy. New York: Russell Sage Foundation.

Khalid, A.M., \& Hanif, M.N. (2005). Corporate governance for banks in Pakistan: recent developments and regional comparisons. CMER Working Paper Series, 5-42.

Lewis, S., Gambles, R., \& Rapoport, R. (2007). The constraints of a work-life balance approach: an international perspective. The International Journal of Human Resource Management, 18(3), 360-373.

Lockwood, N. (2003). Work/Life Balance: Challenges and Solutions. Alexandria: Society for Human Resource Management.

Lyons, S.T., Duxbury, L. E., \& Higgins, C. (2006). A comparison of the values and commitment of private sector, public sector, and parapublic sector employees. Public Administration Review, 66(4), 605-618.

Parasuraman, S., \& Greenhaus, J. H. (2002). Toward reducing some critical gaps in workfamily research. Human Resource Management Review, 12(3), 299-312.

Parus, B. (2000). Measuring the ROI of work/life programs. Workspan, 43(9), 50-54. 
Premeaux, S.F., Adkins, C.L., \& Mossholder, K.W. (2007). Balancing work and family: a field study of multi-dimensional, multi-role work-family conflict. Journal of Organizational Behavior, 28(6), 705-727.

Stevens, J.P. (2002). Applied multivariate statistics for the social sciences (4th ed.). Hillsdale, NJ: Lawrence Erlbaum Associates.

Taylor, R. (2002). The future of work-life balance. Swindon: Economic and Social Research Council.

Thompson, C. A., Beauvais, L. L., \& Lyness, K. S. (1999). When work-family benefits are not enough: the influence of work-family culture on benefit utilization, organizational attachment, and work-family conflict. Journal of Vocational Behavior, 54(3), 392415.

Williams, J. (2000). Unbending gender: why family and work conflict and what to do about it. New York: Oxford University Press. 


\section{Appendix}

Table 1

\begin{tabular}{|l|l|l|}
\hline \multicolumn{2}{|l|}{ KMO and Bartlett's Test } \\
\hline \multirow{2}{*}{ Kaiser-Meyer-Olkin Measure of Sampling Adequacy. } & .885 \\
\hline Bartlett's Test of Sphericity & Approx. Chi-Square & 3825.807 \\
\cline { 2 - 3 } & Df & 105 \\
\cline { 2 - 3 } & Sig. & .000 \\
\hline
\end{tabular}

Table 2

\begin{tabular}{|c|c|c|c|c|c|c|c|}
\hline \multicolumn{8}{|c|}{ Total Variance Explained } \\
\hline \multirow[t]{2}{*}{ Component } & \multicolumn{3}{|c|}{ Initial Eigenvalues } & \multicolumn{3}{|c|}{$\begin{array}{c}\text { Extraction Sums of Squared } \\
\text { Loadings }\end{array}$} & \multirow{2}{*}{$\begin{array}{r}\text { Rotation } \\
\text { Sums of } \\
\text { Squared } \\
\text { Loadings }\end{array}$} \\
\hline & Total & $\begin{array}{c}\% \text { of } \\
\text { Variance }\end{array}$ & $\begin{array}{c}\text { Cumulative } \\
\%\end{array}$ & Total & $\begin{array}{c}\% \text { of } \\
\text { Variance }\end{array}$ & $\begin{array}{c}\text { Cumulative } \\
\%\end{array}$ & \\
\hline 1 & 7.439 & 49.595 & 49.595 & 7.439 & 49.595 & 49.595 & 6.828 \\
\hline 2 & 1.775 & 11.831 & 61.426 & 1.775 & 11.831 & 61.426 & 3.934 \\
\hline 3 & 1.298 & 8.650 & 70.076 & 1.298 & 8.650 & 70.076 & 4.141 \\
\hline 4 & .773 & 5.151 & 75.227 & & & & \\
\hline 5 & .676 & 4.504 & 79.732 & & & & \\
\hline 6 & .597 & 3.981 & 83.713 & & & & \\
\hline 7 & .547 & 3.649 & 87.361 & & & & \\
\hline 8 & .412 & 2.750 & 90.111 & & & & \\
\hline 9 & .356 & 2.375 & 92.486 & & & & \\
\hline 10 & .279 & 1.860 & 94.346 & & & & \\
\hline 11 & .248 & 1.656 & 96.002 & & & & \\
\hline 12 & .186 & 1.238 & 97.240 & & & & \\
\hline 13 & .171 & 1.138 & 98.378 & & & & \\
\hline 14 & .144 & .960 & 99.339 & & & & \\
\hline 15 & .099 & .661 & 100.000 & & & & \\
\hline
\end{tabular}


Table 3

\begin{tabular}{|c|c|c|c|}
\hline \multicolumn{4}{|l|}{ Pattern Matrixa } \\
\hline \multirow[b]{2}{*}{ Questions } & \multicolumn{3}{|c|}{ Component } \\
\hline & $\begin{array}{l}\text { Work/life } \\
\text { balance }\end{array}$ & $\begin{array}{l}\text { Support } \\
\text { from } \\
\text { others }\end{array}$ & $\begin{array}{l}\text { Organizational } \\
\text { Support }\end{array}$ \\
\hline $\begin{array}{l}\text { 7. Do you spend more hours at work than the official } \\
\text { work timings of your organization? }\end{array}$ & .818 & & \\
\hline $\begin{array}{l}\text { 8. Do you take your official work home as well for } \\
\text { completion? }\end{array}$ & .772 & & \\
\hline $\begin{array}{l}\text { 9. Does the thought of work worries or bothers you } \\
\text { when you are not at work? }\end{array}$ & .791 & & \\
\hline $\begin{array}{l}\text { 10. Are you able to give time to yourself because of } \\
\text { work? }\end{array}$ & .891 & & \\
\hline $\begin{array}{l}\text { 11. Are you able to give time to your family because } \\
\text { of work? }\end{array}$ & .881 & & \\
\hline $\begin{array}{l}\text { 12. Are you able to give time to your friends because } \\
\text { of work? }\end{array}$ & .892 & & \\
\hline $\begin{array}{l}\text { 13. Do you spend time for recreational activities after } \\
\text { work? }\end{array}$ & .861 & & \\
\hline $\begin{array}{l}\text { 16. Does your organization have any policies that } \\
\text { help in maintaining a proper Work/life balance? }\end{array}$ & & & -.873 \\
\hline $\begin{array}{l}\text { 17. Do you think your organization should come up } \\
\text { with better policies or improve the current ones to } \\
\text { provide a good Work/life balance? }\end{array}$ & & & -.915 \\
\hline 19. Do you work during Rest and Recreational leave? & .718 & & \\
\hline $\begin{array}{l}\text { 20. Does your organization arrange social functions } \\
\text { like annual/formal dinner for you and your family? }\end{array}$ & & & -.765 \\
\hline $\begin{array}{l}\text { 21. Do you feel that your family life demands more } \\
\text { time from you that makes it difficult to spend time at } \\
\text { work? }\end{array}$ & & .502 & \\
\hline $\begin{array}{l}\text { 22. Do you feel that your social life demands more } \\
\text { time from you that makes it difficult to spend time at } \\
\text { work? }\end{array}$ & & .817 & \\
\hline $\begin{array}{l}\text { 23. Does your family support you in balancing your } \\
\text { work and non-work commitments? }\end{array}$ & & .744 & \\
\hline $\begin{array}{l}\text { 24. Do your friends support you in balancing your } \\
\text { work and non-work commitments? }\end{array}$ & & .832 & \\
\hline \multicolumn{4}{|l|}{$\begin{array}{l}\text { Extraction Method: Principal Component Analysis. } \\
\text { Rotation Method: Oblimin with Kaiser Normalization. }\end{array}$} \\
\hline a. Rotation converged in 8 iterations & & & \\
\hline
\end{tabular}


Table 4

\begin{tabular}{|l|c|c|c|c|c|}
\hline \multicolumn{1}{|c|}{ Constructs } & N & Minimum & Maximum & Mean & $\begin{array}{c}\text { Std. } \\
\text { Deviation }\end{array}$ \\
\hline Work/life balance & 348 & 1.00 & 4.86 & 2.85 & 0.83 \\
\hline Organizational support & 348 & 1.25 & 4.00 & 2.44 & 0.58 \\
\hline Support from others & 348 & 1.50 & 4.50 & 2.68 & 0.66 \\
\hline
\end{tabular}

Table 5

\begin{tabular}{|c|c|c|c|c|}
\hline \multicolumn{5}{|c|}{ Correlations } \\
\hline & & WLB & $\mathrm{OS}$ & SFO \\
\hline \multirow{3}{*}{$\begin{array}{l}\text { Work/life } \\
\text { balance }\end{array}$} & Pearson Correlation & 1 & $.635^{* *}$ & $.504 * *$ \\
\hline & Sig. (2-tailed) & & .000 & .000 \\
\hline & $\mathrm{N}$ & 348 & 348 & 348 \\
\hline \multirow{4}{*}{$\begin{array}{l}\text { Organizational } \\
\text { support }\end{array}$} & Pearson Correlation & $.635 * *$ & 1 & $.491 * *$ \\
\hline & Sig. (2-tailed) & .000 & & .000 \\
\hline & $\mathrm{N}$ & 348 & 348 & 348 \\
\hline & Pearson Correlation & $.504 * *$ & $.491 * *$ & 1 \\
\hline \multirow{2}{*}{$\begin{array}{l}\text { Support from } \\
\text { others }\end{array}$} & Sig. (2-tailed) & .000 & .000 & \\
\hline & $\mathrm{N}$ & 348 & 348 & 348 \\
\hline
\end{tabular}


Table 6

\begin{tabular}{|c|c|c|c|c|c|}
\hline \multicolumn{6}{|c|}{ Correlations } \\
\hline \multicolumn{3}{|l|}{ 1. Gender } & WLB & OS & SFO \\
\hline \multirow{9}{*}{ Males } & \multirow{3}{*}{ Work/life balance } & Pearson Correlation & 1 & $.487 * *$ & $.404 * *$ \\
\hline & & Sig. (2-tailed) & & .000 & .000 \\
\hline & & $\mathrm{N}$ & 210 & 210 & 210 \\
\hline & \multirow{3}{*}{ Organizational support } & Pearson Correlation & $.487 * *$ & 1 & $.475 * *$ \\
\hline & & Sig. (2-tailed) & .000 & & .000 \\
\hline & & $\mathrm{N}$ & 210 & 210 & 210 \\
\hline & \multirow{3}{*}{ Support from others } & Pearson Correlation & $.404 * *$ & $.475^{* * *}$ & 1 \\
\hline & & Sig. (2-tailed) & .000 & .000 & \\
\hline & & $\mathrm{N}$ & 210 & 210 & 210 \\
\hline \multirow{9}{*}{ Females } & \multirow{3}{*}{ Work/life balance } & Pearson Correlation & 1 & $.664 * *$ & $.668 * *$ \\
\hline & & Sig. (2-tailed) & & .000 & .000 \\
\hline & & $\mathrm{N}$ & 138 & 138 & 138 \\
\hline & \multirow{3}{*}{ Organizational support } & Pearson Correlation & $.664 * *$ & 1 & $.462 * *$ \\
\hline & & Sig. (2-tailed) & .000 & & .000 \\
\hline & & $\mathrm{N}$ & 138 & 138 & 138 \\
\hline & \multirow{3}{*}{ Support from others } & Pearson Correlation & $.668 * *$ & $.462 * *$ & 1 \\
\hline & & Sig. (2-tailed) & .000 & .000 & \\
\hline & & $\mathrm{N}$ & 138 & 138 & 138 \\
\hline
\end{tabular}


Table 7

\begin{tabular}{|c|c|c|c|c|c|c|c|c|c|c|}
\hline \multicolumn{11}{|c|}{ Independent Samples Test } \\
\hline & & \multicolumn{2}{|c|}{$\begin{array}{l}\text { Levene's } \\
\text { Test for } \\
\text { Equality of } \\
\text { Variances }\end{array}$} & \multicolumn{7}{|c|}{ t-test for Equality of Means } \\
\hline & & \multirow[t]{2}{*}{$\mathrm{F}$} & \multirow[t]{2}{*}{ Sig. } & \multirow[t]{2}{*}{$\mathrm{t}$} & \multirow[t]{2}{*}{ df } & \multirow[t]{2}{*}{$\begin{array}{l}\text { Sig. } \\
(2- \\
\text { tailed })\end{array}$} & \multirow[t]{2}{*}{$\begin{array}{c}\text { Mean } \\
\text { Difference }\end{array}$} & \multirow[t]{2}{*}{$\begin{array}{l}\text { Std. Error } \\
\text { Difference }\end{array}$} & \multicolumn{2}{|c|}{$\begin{array}{l}95 \% \text { Confidence } \\
\text { Interval of the } \\
\text { Difference }\end{array}$} \\
\hline & & & & & & & & & Lower & Upper \\
\hline \multirow{2}{*}{$\begin{array}{l}\text { Work/ } \\
\text { life } \\
\text { balance }\end{array}$} & $\begin{array}{l}\text { Equal } \\
\text { variances } \\
\text { assumed } \\
\end{array}$ & .401 & .527 & -12.953 & 346 & .000 & -.96534 & .07453 & -1.11192 & -.81875 \\
\hline & $\begin{array}{l}\text { Equal } \\
\text { variances } \\
\text { not } \\
\text { assumed }\end{array}$ & & & -12.887 & 288.109 & .000 & -.96534 & .07491 & -1.11278 & -.81790 \\
\hline \multirow{2}{*}{$\begin{array}{l}\text { Organiza } \\
\text {-tional } \\
\text { suppose }\end{array}$} & $\begin{array}{l}\text { Equal } \\
\text { variances } \\
\text { assumed }\end{array}$ & 2.386 & .123 & -7.074 & 346 & .000 & -.42422 & .05997 & -.54217 & -.30627 \\
\hline & $\begin{array}{l}\text { Equal } \\
\text { variances } \\
\text { not } \\
\text { assumed }\end{array}$ & & & -6.867 & 263.323 & .000 & -.42422 & .06178 & -.54586 & -.30258 \\
\hline \multirow{2}{*}{$\begin{array}{l}\text { Support } \\
\text { from } \\
\text { others }\end{array}$} & $\begin{array}{l}\text { Equal } \\
\text { variances } \\
\text { assumed } \\
\end{array}$ & 1.309 & .253 & -3.320 & 346 & .001 & -.23499 & .07077 & -.37419 & -.09579 \\
\hline & $\begin{array}{l}\text { Equal } \\
\text { variances } \\
\text { not } \\
\text { assumed }\end{array}$ & & & -3.415 & 319.507 & .001 & -.23499 & .06881 & -.37037 & -.09961 \\
\hline
\end{tabular}

